\title{
Intention of Vietnamese Enterprises's digital transformation
}

\author{
Thi Hong Nga, Nguyen \\ Hanoi University of Industry \\ Hanoi, Vietnam \\ nguyenthihongnga@haui.edu.vn
}

\author{
Dinh Khoa, $\mathrm{Vu}$ \\ Hanoi University of Industry \\ Hanoi, Vietnam \\ vudinhkhoa@haui.edu.vn
}

\author{
Dac Thanh, Nguyen \\ Thuongmai University \\ Hanoi, Vietnam \\ thanhnd@tmu.edu.vn
}

\begin{abstract}
There have been many studies on digital transformation in recent times, but these studies focused on clarifying the concept, content, and implementation of digital transformation. There have not been many studies on the attitudes and intentions of enterprises to digital transformation (DT). This paper proposes factors affecting DT intention including perceived usefulness, trust, innovation, perceived risk to investigate attitudes about DT and examines the impaction of attitude and subject norms factors on the digital transformation intention of enterprises. A questionnaire designed and sent to 337 Vietnamese enterprises in different fields of activity. This study uses Structural Equation Model (SEM). The perceived usefulness, Innovation factors effect to the attitude possitively leading to the Intention of DT of enterprises, whereas the perception of pisk has a negative impact. Attitudes towards digital transformation and Subjective Norms have a positive impact on digital transformation intention. This paper helps Vietnamese government authorities to have a basis to promote and support Vietnamese enterprises in digital transformation.
\end{abstract}

Index Terms-digital transformation, intention, Technology Acceptance Model (TAM)

\section{INTRODUCTION}

$\mathrm{T}$ $\mathrm{HE} 4^{\text {th }}$ industrial revolution is one of the most common topics in both industry and academy. The $4^{\text {th }}$ industrial revolution plays a considerable role in digitalization. "The main motivation of DT is to raise the efficiency and productivity to improve the competitive capacity of the enterprises" [1]. In some decades, DT has emerged as a significant phenomenon in strategic information systems research $[2,3]$ and for practitioners $[4,5]$. DT covers the changes which occur in society and industries by using of digital technologies [6, 7]. DT has been explained that companies must consider how to do to innovate technology by proposing DT strategies to promote operational performance [8].

In Vietnam, the government has been paying great attention to comprehensive digital transformation. This paper studies whether Vietnamese enterprises are interested in DT and what factors affect the DT intention of Vietnamese enterprises. Research on digital transformation approach from many different aspects, focusing on clarifying the concept and nature of DT, content of DT, impact of DT on business administration, value chain, efficiency, ... Researching on the factors affecting DT intention, especially in emerging economies is necessary. The motivation of this research is examining the factors impacting DT intention of Vietnamese enterprises. We hope the research results will help state management agencies take measures to support and promote the digital transformation process of enterprises.

\section{Literature Review And Conceptual Framework}

\section{Digital transformatiom}

Although DT is a common discussion now, the think of digital products and services has been deeply understood in the past two decades $[9,10]$. Researchers offer different definitions of DT. Bowersox et al. defined DT is a process of regenerating a business to digitize operations and form extended supply chain relationships [11]. Westerman et al. showed that DT is using of technology to have a radical improvement about the performance of enterprise [5]. They use social media, analytic, mobility, smart embedded devices to transform relationships with customers and internal process. Others define DT to rebuild a business model according to customer needs using new technologies [12]. DT points out the basic transformation of the business world through the creation of new internet-based technologies that have an effect on whole society. DT is the intentional digital evolution of an enterprise in strategic and tactic. Schallmo et al. considered DT as the consistency network of of the economy as a whole and adjusting players to the digital economy [13]. Mergel et al. define DT is the modification of core government processes and services as a whole, beyond traditional digitizations [14]; it transforms continuously taking into consideration current policies, procedures, user needs, and leads to complete modification of existing digital services as well as creation of technical services; the result of DT is focused on satisfying customer needs, new forms of service provision and expanding user base.

Definitions of DT, involve using new technologies to rebuild business models according to customer 
requirements. However, in the public sector, DT not only creates new business model but also efforts to make services more efficient, and peple can access easier [15].

2. Theory of reasoned action

This theory refers the impaction of Attitudes to human behaviors. Researchers often use to predict how someone will behave through their attitudes and behavioral intentions before they perform that behavior. The decision of an individual to participate in a specific behavior through the result that the individual expects to arrive because of the conduct of the behavior. According to TRA, the primary behavior can be predicted according to the individual's attitude towards the behavior being addressed through the intervention effect of behavioral intention. In this theoretical model, both personal attitudes and social or regulatory factors have an impact to behavioral intention, which is the most powerful predictor of actual behavior.

3. Theory of planned behavior (TPB)

Ajzen developed TPB from TRA [16], it assums that a behavior be predicted or explained by behavioral tendency in order to make such behaviors. The behavioral trends are assumed including motivating factors that impact behavior, and he defined it as the level of effort that people try to make that behavior [16]. Behavioral tendency has three factors. First, Attitude is viewed as a positive or negative assessment of the behavior. Second, Social impact which mentions to social pressure experienced to make such behavior. Finally, Ajzen developed TPB through adding a sensory behavior control element into the TRA. The perceived behavioral control element reflects ease or difficulty in making behavior; it depends on available resources and opportunities to making the behavior. TPB has been widely used in many areas of behavioral prediction researchs [17]. The TPB is a useful theory for preemployment assessments of degree of readiness for change because it can provide organizations with information on employee beliefs early and the determinants of their intentions for change [18].

4. TAM

It is the most common models of predictive research about the use IT systems of users. Davis developed TAM [19, 20]. TAM is an adaptation for TRA in 1986. The TAM includes "perceived usefulness" (PU) and "perceived ease of use" (PEU), these have a considerable effect on the application of new technology. TAM has been extensively researched and validated by various studies to test the adoption of individual technology in various information system structures. According to TAM, PEU and PU factors are the most important determinants of using a system. Using attitude is related to the user's assessment of the desired behavior using a particular system application. Many studies on factors affecting behavioral intention have been based on TAM.

Because TAM explains well the difference in the willingness of consumers to accept technology and it is one of the most commonly used models in the researchs on the application of technology [21].

\section{6. $P U$}

"PU is used a lot in the process of information system applying which is considered as an extent to which a consumer's use of new technology to improve work efficiency" [19]. In this research, PU refers to enterprises's choice to adopt the DT if they believe the adoption of DT can has positive influences.

Many empirical researchs on the application of new technology in some past decades pointed out that PU has a positive impact on user's intention [22]. We have a hypothesis:

Hypothesis 1 (H1): PU has a positive effect on attitudes (AT) related to the intention of DT.

7. Trust (TRU)

TRU is an important variable of application research along with PU and PEU. TRU impacts the attitudes of potential users and their willingness to apply. TRU has been studied by researchers from many empirical studies in many difference fields [23-26]... users' trust impact behaviors [27]. Many researchers showed that TRU has an important role in the user's intention. We have a following hypothesis:

Hypothesis 2 (H2): TRU impacts on AT toward the intention of DT

\section{Perceived Risk (PR)}

Most researchers think that PR is a factor which negatively impact to application of technology [27]. PR mentions to the risk that the user is aware of when he adopts DT. The level of risk perception is an important factor impacting application [28]. PR can considerably affect users' willingness to DT. We have the following hypothesis:

Hypothesis 3 (H3): PR will negatively impact to AT toward the intention of DT

\section{User Innovativeness}

"Innovativeness is understood as the degree of early acceptance of an innovation to try new products, technologies or services" [29]. When an individual has an innovativeness, he has a more positive intention to adopt. People are less probable to PR and more open-minded to technological innovation. "Innovativeness is a basic feature of human beings, which reflects the degree of interest of users in a new field" [30]. Individuals' innovation is important in their intention to use, empirical studies have demonstrated this [31]. We have hypothesis:

Hypothesis 4 (H4): Innovativeness (INN) impacts on AT toward the intention of DT

10. Attitudes (AT)

AT mentions the user's opinion and personal trend. "Behavior intention is the power of one's intention to make a specific behavior" [32]. A positive AT toward new technology is an important to apply that technology [33]. TAM shows AT impacts on users' application intentions. Many different researchs have been applied this model. Thus, we have hypothesis:

Hypothesis 5 (H5): Attitudes (AT) has a significant positive impact on intention of DT (INT)

11. Subjective Norms (SN) 
Following Ajzen \& Fishbein SN refers to a person's perception. when someone influence to him, they are important to him. He thinks that if those people perform the behavior, he will also do it [34]. TPB pointed out SN influences a person's INT [35]. There have been many empirical studies supporting this argumnent [36]. Hence, in this study, we hypothesize:

Hypothesis 6 (H6): Subjective norms (SN) have a positive impact with the intention of DT

\section{METHODOLOGY}

This study collected data from 337 Vietnamese enterprises. Because of Covid-19 pandemic, a survey questionnaire was sent via google form link. According to Bhattacherjee because online survey is considered as a suitable research method nowadays in technological development context, in addition to Covid - 19 pandemic online survey is more safetier than other data collection method [37]. The initial items of these questionnaires were made in English. First questionnaire draft was developed by reviewing systematically extended mix models relevant determinants of behavioural intention to digital transformation, besides in-depth qualitative interview was also used to slightly modify based on the view of the firm's manager from various sectors. These practitioners assessed the validity of measurement scale. These opinions from the practitioner's help ensure the meaning of the original scale and develop the scale in order to meet the fit of this study.

Sample size was calculated using hair et al, according to this formula the minimum is calculated by 5 multiple items, so 40 items the number of respondents is more than 200 people. with 337 Vietnamese firms that meet the demand [37].

\section{RESULTS}

In general Cronbach's alpha value has been considered as criteria of the reliability analysis of constructs. According to statistical experts, Cronbach's alpha values ranged from .672 to .968 , which is consistent with the measures. Next step this study conducted EFA using PAF with promax rotation. After analyzing EFA 6 factors with Eigenvalues higher than 1, giving an explanation for $76,724 \%$ of the variance. In addition, factor loading values were higher than 0.5 (see table 1 below), so all items in the model were hold further data analysis, therefore the figure shows the acceptable discriminant validity for the latent variable. Following to results from table 1(see below), the AVE values of all latent variables were higher than .60 , and the CR of these latent variables were higher than .80; Fornell \& Larcker pointed out that "the AVE value less than .60, but $\mathrm{CR}$ value is higher than .60 , the convergent validity of the latent variable is still sufficient" [38]. Most of the constructs have AVE values higher than 0.6. The statistical results are consistent (CR coefficients arraying from .842 to .972, AVE are greater than .60)

Table 1: Properties of scales used in the study

\begin{tabular}{|c|c|c|c|c|c|}
\hline & $\begin{array}{c}\text { Indicat } \\
\text { ors }\end{array}$ & FL & $\begin{array}{c}\text { Cronbach's } \\
\text { alpha }\end{array}$ & CR & AVE \\
\hline \multirow{11}{*}{$\begin{array}{l}\text { Perceived } \\
\text { usefulness }\end{array}$} & PU8 & 0,866 & \multirow{11}{*}{0,968} & \multirow{11}{*}{0,968} & \multirow{11}{*}{0,736} \\
\hline & PU3 & 0,849 & & & \\
\hline & PU2 & 0,853 & & & \\
\hline & PU4 & 0,861 & & & \\
\hline & PU5 & 0,877 & & & \\
\hline & PU9 & 0,880 & & & \\
\hline & PU6 & 0,866 & & & \\
\hline & PU10 & 0,829 & & & \\
\hline & PU1 & 0,840 & & & \\
\hline & PU7 & 0,847 & & & \\
\hline & PU11 & 0,865 & & & \\
\hline \multirow{6}{*}{$\begin{array}{l}\text { Perceived } \\
\text { Risk }\end{array}$} & PR4 & 0,896 & \multirow{6}{*}{0,672} & \multirow{6}{*}{0,946} & \multirow{6}{*}{0.745} \\
\hline & PR3 & 0,880 & & & \\
\hline & PR6 & 0,882 & & & \\
\hline & PR1 & 0,858 & & & \\
\hline & PR2 & 0,805 & & & \\
\hline & PR5 & 0,856 & & & \\
\hline \multirow{4}{*}{$\begin{array}{l}\text { User } \\
\text { Innovativen } \\
\text { ess }\end{array}$} & INN2 & 0,793 & \multirow{4}{*}{0,883} & \multirow{4}{*}{0,882} & \multirow{4}{*}{0,653} \\
\hline & INN1 & 0,739 & & & \\
\hline & INN3 & 0,830 & & & \\
\hline & INN4 & 0,864 & & & \\
\hline \multirow[t]{4}{*}{ Attitudes } & AT3 & 0,890 & \multirow{4}{*}{0,919} & \multirow{4}{*}{0,909} & \multirow{4}{*}{0,715} \\
\hline & AT1 & 0,917 & & & \\
\hline & AT2 & 0,846 & & & \\
\hline & AT4 & 0,716 & & & \\
\hline Subjective & SN2 & 0,908 & & & \\
\hline
\end{tabular}




\begin{tabular}{|l|l|l|l|l|l|}
\hline \multirow{2}{*}{ Norms } & SN1 & 0,818 & 0,907 & 0,812 & 0,6 \\
\cline { 2 - 3 } & SN3 & 0,551 & & & \\
\hline \multirow{3}{*}{$\begin{array}{l}\text { Intention of } \\
\text { DT }\end{array}$} & INT1 & 0,819 & \multirow{2}{*}{0,837} & 0,821 & 0,606 \\
\cline { 2 - 3 } & INT2 & 0,824 & & & \\
\cline { 2 - 3 } & INT3 & 0,684 & & & \\
\hline
\end{tabular}

Overall evaluation

CFA technique with AMOS 20 tools is used to measure the psychometric properties of all the scales, prior to hypothesis testing. As can be seen from the table 2, four-factor and 30items a measurement model fit the data satisfactorily: $\mathrm{CFI}=0.959 ; \quad \mathrm{TLI}=0.952 ; \quad \mathrm{RMSEA}=0.054 ; \quad \mathrm{RMR}=$ $0.070 ; \quad \chi 2 / d f=1.987$; that means better than their recommended cut-off values (CFI $>.90 ;$ TLI $>.90$; RMSEA < .80; RMR < .80) [40]. Overall, the model index meets the standards.

Table 2: Model fit indicators

\begin{tabular}{|c|c|c|}
\hline Model fit & Recommended value & Actual value \\
\hline Chi - square/df & $<=3$ & 1,987 \\
GFI & $>=0.8$ & 0.873 \\
AGFI & $>=0.8$ & 0.843 \\
NFI & $>=0.9$ & 0.920 \\
CFI & $>=0.9$ & 0.959 \\
IFI & $>=0.9$ & 0.959 \\
TLI & $>=0.9$ & 0.952 \\
RMSEA & $<0.08$ & 0.54 \\
RMSR & $<=0.1$ & 0.07 \\
\hline
\end{tabular}

This paper use SEM to estimate the correlation among the 6 latent variables. According to Anderson and Gerbing "the minimum sample size required for SEM is greater than 200 observations" [41]. This paper collected 377 observations. It meets the requirement of SEM.

After assessing the reliability and validity, SEM needs to be estimated to analyze the predicted structural relationships.
This is consistent with [42] regarding the two-stage process in hypothesis testing. The results point out that the model is suitable: $\quad$ CFI $=0.959 ; \quad$ TLI $=0.952 ; \quad$ RMSEA $=0.054$; $\mathrm{RMR}=0.070 ; \chi 2=794.812 ; \mathrm{df}=400, \mathrm{p}<0.05 ;$ [39]

Fig. 1: SEM estimation results

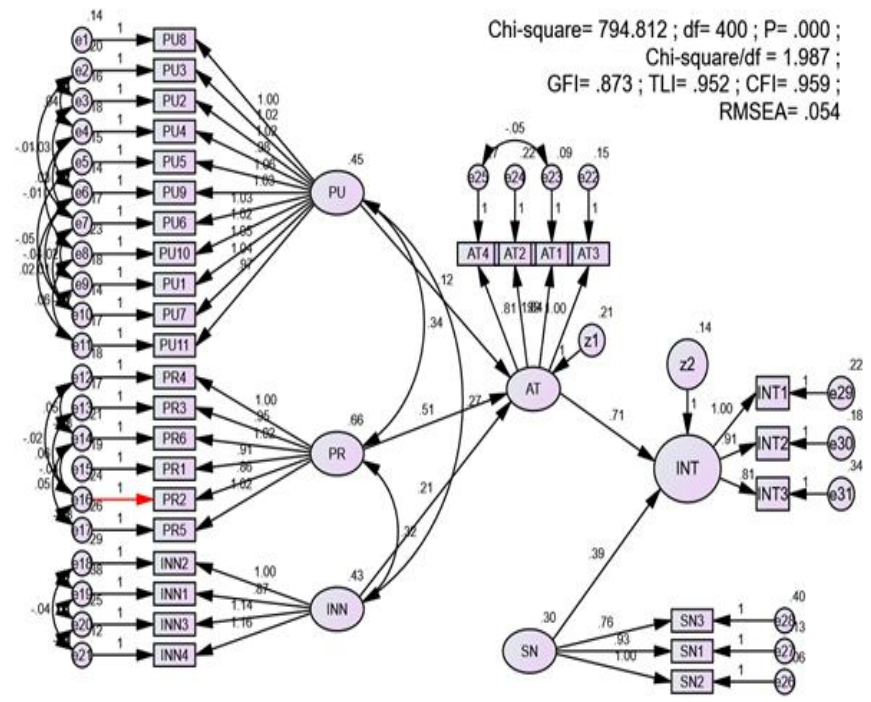

Hypothesis testing

\begin{tabular}{|c|c|c|c|c|c|c|c|}
\hline & & & Estimate & S.E. & C.R. & P & $\begin{array}{l}\text { standardized } \\
\text { estimte }\end{array}$ \\
\hline AT & $<-$ & PU & .121 & .060 & 2.013 & .044 & .111 \\
\hline AT & $<-$ & PR & -.510 & .054 & 9.446 & $* * *$ & -.569 \\
\hline AT & $<-$ & INN & .205 & .064 & 3.204 & .001 & .184 \\
\hline INT & $<-$ & AT & .707 & .050 & $\begin{array}{r}14.26 \\
0\end{array}$ & **** & .763 \\
\hline INT & $<-$ & SN & .389 & .058 & 6.729 & $* * *$ & .317 \\
\hline
\end{tabular}

The results for the hypothesis testing are represented in Table 3 above. All of the hypotheses are accepted. Specifically, $\mathrm{H} 1$ predicts $\mathrm{PU}$ has a positive effect on AT, is supported (standardized $\beta=.111, p=.044<0.05$ ). H3 suggested that PR will negatively impact to AT toward the intention of DT, is also supported (standardized $\beta=.569$, $p=.000<0.05$ ). H4 is also supported, which argued that there is a positive effect between INN and AT (standardized $\beta=.184, p=.001<0.05)$. H5, which argued that there is positively effect between AT and INT (intention to DT) (standardized $\beta=.763, p=.000<0.05$ ). H6, which 
contended that SN impacts positively to INT (standardized $\beta=.317, p=.000<0.05)$.). In conclusion all of the hypotheses were accepted.

Table 4: Squared Multiple Correlations of SEM model (Group number 1 - Default model)

\begin{tabular}{|l|r|}
\hline & Estimate \\
\hline AT & .601 \\
INT & .683 \\
\hline
\end{tabular}

3 factors perceived usefulness, perceived risk and User Innovativeness explained $60,1 \%$ variation of attitudes of Vietnamese firms. Besides, intention to digital transformation was explained by attitudes and subjective norms, this was quite rational in the TPB model.

\section{DISCUSSION AND CONCLUSIONS}

Covid-19 epidemic has brought difficulties for economies all over the world. Vietnam economy has also experienced the loss. Digital transformation can be seen as a solution for enterprises to recover from crisis quickly. This study investigates the intention of digital transformation and proposes the model that explains the determinant factors of digital transformation intention based on TRA, TPB theories and TAM. The results of this study indicate that perceived usefulness and trust positively affect attitudes toward digital transformation while perceived risk negatively influences attitudes. These results are aligned with other previous studies [27], [29]. It is said that when managers believe in the benefit of digital transformation, their intention will be strengthened. Besides, our study also confirms that attitudes and subjective norms have a positive impact on digital transformation intention. Our study provides practitioners and academics with essential insights in the mechanism of decision making on digital transformation. We belived that digital transformation can be applied broadly in every field of organization management. It is necessary to understand which factors are determinants of digital transformation intention. When using new technology, the attitudes toward that experience can be formed. If it is a useful experience, the attitudes will be positive. Moreover, the belief toward usefulness of digital transformation can lead attitudes to become more positive, which, in turn, can lead users to the decision more quickly. In contrast, when users perceive any risk or harm, they will deny it. That can deter the decision to transform. At organizational levels, managers are expected to change their mind-sets to more risk-taking acceptance and more experiencing the benefits of digital transformation. Besides, to reduce the reluctance to change, there is a need to exchange information and ideas in virtual communities and networks. When managers understand the benefits of digital transformation and perceive it from others, their intention will become stronger and lead to real actions.

\section{LIMITATIONS AND FUTURE DIRECTIONS}

Inspire of providing some contributions to the research field, our study still has some limitations. First, as sample used in this study is c is cross-sectional data, which may cause aberration when applied in a specific sector. Future studies could replicate this study in a particular industry to produce a better understanding of the factors in the proposed research model. Second, this study stressed only on the direct effects and does not consider whether there are any indirect effects. Further studies could explore the mediating effect of attitudes in the relationship between other factors and intention of digital transformation to get better understanding. Finally, this study did not control for firm size, which can cause some differences when firms apply digital transformation. Future research can pay attention to it to compare the differences between big firms and SMEs.

\section{REFERENCES}

[1] A. Ustundag and E. Cevikcan, Industry 4.0: managing the digital transformation. Springer, 2017.

[2] A. Bharadwaj, O. A. El Sawy, P. A. Pavlou, and N. v. J. M. q. Venkatraman, "Digital business strategy: toward a next generation of insights," pp. 471-482, 2013.

[3] G. Piccinini, Physical computation: A mechanistic account. OUP Oxford, 2015.

[4] M. Fitzgerald, N. Kruschwitz, D. Bonnet, and M. J. M. s. m. r. Welch, "Embracing digital technology: A new strategic imperative," vol. 55, no. 2, p. 1, 2014.

[5] G. Westerman, M. Tannou, D. Bonnet, P. Ferraris, A. J. M. M. McAfee, and M. Capgemini Consulting, "The Digital Advantage: How digital leaders outperform their peers in every industry," vol. 2, pp. 2-23, 2012.

[6] R. Agarwal, G. Gao, C. DesRoches, and A. K. J. I. s. r. Jha, "Research commentary-The digital transformation of healthcare: Current status and the road ahead," vol. 21, no. 4, pp. 796-809, 2010.

[7] A. Majchrzak, M. L. Markus, and J. J. M. q. Wareham, "Designing for digital transformation: Lessons for information systems research from the study of ICT and societal challenges," vol. 40, no. 2, pp. 267-277, 2016

[8] T. Hess, C. Matt, A. Benlian, and F. J. M. Q. E. Wiesböck, "Options for formulating a digital transformation strategy," vol. 15, no. 2, 2016.

[9] L. Heilig, S. Schwarze, and S. Voß, "An analysis of digital transformation in the history and future of modern ports," 2017.

[10] D. R. Schallmo and C. A. Williams, "History of digital transformation," in Digital Transformation Now!: Springer, 2018, pp. 3-8

[11] D. J. Bowersox, D. J. Closs, and R. W. J. S. C. M. R. Drayer, "The digital transformation: technology and beyond," vol. 9, no. 1, pp. 22-29, 2005

[12] S. J. J. S. Berman and Leadership, "Digital transformation: opportunities to create new business models," 2012.

[13] D. Schallmo, C. A. Williams, and L. J. D. D. I. Boardman, "Digital transformation of business models-best practice, enablers, and roadmap," pp. 119-138, 2020.

[14] I. Mergel, N. Edelmann, and N. J. G. i. q. Haug, "Defining digital transformation: Results from expert interviews," vol. 36, no. 4, p. 101385, 2019. 
[15] A. Meijer and V. J. G. I. Q. Bekkers, "A metatheory of egovernment: Creating some order in a fragmented research field," vol. 32, no. 3, pp. 237-245, 2015

[16] I. J. O. b. Ajzen and h. d. processes, "The theory of planned behavior," vol. 50, no. 2, pp. 179-211, 1991.

[17] C. J. Armitage and M. J. B. j. o. s. p. Conner, "Efficacy of the theory of planned behaviour: A meta-analytic review," vol. 40, no. 4, pp. 471-499, 2001.

[18] N. L. Jimmieson, M. Peach, and K. M. J. T. j. o. a. b. s. White, "Utilizing the theory of planned behavior to inform change management: An investigation of employee intentions to support organizational change," vol. 44, no. 2, pp. 237-262, 2008.

[19] F. D. Davis, "A technology acceptance model for empirically testing new end-user information systems: Theory and results," Massachusetts Institute of Technology, 1985.

[20] F. D. Davis, R. P. Bagozzi, and P. R. J. M. s. Warshaw, "User acceptance of computer technology: A comparison of two theoretical models," vol. 35, no. 8, pp. 982-1003, 1989.

[21] T. Oliveira and M. F. J. E. J. o. I. S. E. Martins, "Literature review of information technology adoption models at firm level," vol. 14, no. 1, pp. pp110-121-pp110-121, 2011

[22] M. S. Featherman and P. A. J. I. j. o. h.-c. s. Pavlou, "Predicting e-services adoption: a perceived risk facets perspective," vol. 59, no. 4, pp. 451-474, 2003

[23] Z. Hu, S. Ding, S. Li, L. Chen, and S. Yang, "Adoption intention of fintech services for bank users: An empirical examination with an extended technology acceptance model," Symmetry, vol. 11 , no. 3, p. 340, 2019

[24] M. K. Lee and E. Turban, "A trust model for consumer internet shopping," International Journal of electronic commerce, vol. 6, no. 1 , pp. 75-91, 2001.

[25] J. D. Lewis and A. Weigert, "Trust as a social reality," Social forces, vol. 63, no. 4, pp. 967-985, 1985

[26] D. H. McKnight and N. L. Chervany, "What trust means in ecommerce customer relationships: An interdisciplinary conceptual typology," International journal of electronic commerce, vol. 6, no. 2, pp. 35-59, 2001.

[27] A. Kesharwani and S. S. J. I. j. o. b. m. Bisht, "The impact of trust and perceived risk on internet banking adoption in India: An extension of technology acceptance model," 2012.

[28] H. R. Khedmatgozar and A. J. E. C. R. Shahnazi, "The role of dimensions of perceived risk in adoption of corporate internet banking by customers in Iran," vol. 18, no. 2, pp. 389-412, 2018.

[29] T. Leicht, A. Chtourou, and K. B. J. T. J. o. H. T. M. R. Youssef "Consumer innovativeness and intentioned autonomous car adoption," vol. 29, no. 1, pp. 1-11, 2018.

[30] A. Adeiza, N. Azizi Ismail, and M. J. I. J. o. M. S. Marissa Malek, "An empirical examination of the major relationship factors affecting franchisees' overall satisfaction and intention to stay," vol. 10, no. 1, pp. 31-62, 2017.

[31] C. Kim, M. Mirusmonov, and I. J. C. i. h. b. Lee, "An empirical examination of factors influencing the intention to use mobile payment," vol. 26, no. 3, pp. 310-322, 2010.

[32] Z. Hu, S. Ding, S. Li, L. Chen, and S. J. S. Yang, "Adoption intention of fintech services for bank users: An empirical examination with an extended technology acceptance model," vol. 11 , no. 3, p. 340,2019

[33] A. Gupta, N. J. J. o. R. Arora, and C. Services, "Understanding determinants and barriers of mobile shopping adoption using behavioral reasoning theory," vol. 36, pp. 1-7, 2017.

[34] M. Fishbein, J. Jaccard, A. R. Davidson, I. Ajzen, and B. Loken, "Predicting and understanding family planning behaviors," in Understanding attitudes and predicting social behavior: Prentice Hall, 1980.

[35] V. Venkatesh and F. D. J. M. s. Davis, "A theoretical extension of the technology acceptance model: Four longitudinal field studies," vol. 46, no. 2, pp. 186-204, 2000.

[36] A. H. S. J. J. o. F. S. M. Zolait, "An examination of the factors influencing Yemeni Bank users' behavioural intention to use Internet banking services," vol. 15, no. 1, pp. 76-94, 2010.

[37] A. Bhattacherjee, "Social science research: Principles, methods, and practices," 2012.

[38] C. Fornell and D. F. Larcker, "Structural equation models with unobservable variables and measurement error: Algebra and statistics," ed: Sage Publications Sage CA: Los Angeles, CA, 1981.

[39] L. t. Hu and P. M. Bentler, "Cutoff criteria for fit indexes in covariance structure analysis: Conventional criteria versus new alternatives," Structural equation modeling: a multidisciplinary journal, vol. 6, no. 1, pp. 1-55, 1999.

[40] B. Wheaton, B. Muthen, D. F. Alwin, and G. F. Summers, "Assessing reliability and stability in panel models," Sociological methodology, vol. 8, pp. 84-136, 1977.

[41] J. C. Anderson and D. W. Gerbing, "Structural equation modeling in practice: A review and recommended two-step approach," Psychological bulletin, vol. 103, no. 3, p. 411, 1988.

[42] D. W. Gerbing and J. C. Anderson, "Monte Carlo evaluations of goodness of fit indices for structural equation models," Sociological Methods \& Research, vol. 21, no. 2, pp. 132-160, 1992.

[43] T. Leicht, A. Chtourou, and K. B. Youssef, "Consumer innovativeness and intentioned autonomous car adoption," The Journal of High Technology Management Research, vol. 29, no. 1, pp. 1-11, 2018. 